\title{
Utility of Human Immune Responses to GAS Antigens as a Diagnostic Indicator for ARF: A Systematic Review
}

\section{OPEN ACCESS}

Edited by:

Bruno Ramos Nascimento,

Universidade Federal de Minas Gerais, Brazil

Reviewed by:

Sasha A. Singh,

Brigham and Women's Hospital and

Harvard Medical School,

United States

Sarvesh Chelvanambi,

Brigham and Women's Hospital and

Harvard Medical School, United States

*Correspondence: Mark E. Engel

mark.engel@uct.ac.za

Specialty section:

This article was submitted to

Heart Valve Disease,

a section of the journal

Frontiers in Cardiovascular Medicine

Received: 06 April 2021

Accepted: 23 June 2021

Published: 20 July 2021

Citation:

Salie MT, Rampersadh K, Muhamed B, Engel KC, Zühlke LJ, Dale JB and Engel ME (2021) Utility of Human Immune Responses to GAS Antigens as a Diagnostic Indicator for ARF: A Systematic Review. Front. Cardiovasc. Med. 8:691646.

doi: 10.3389/fcvm.2021.691646

\begin{abstract}
M. Taariq Salie ${ }^{1}$, Kimona Rampersadh ${ }^{1}$, Babu Muhamed ${ }^{1,2}$, Kélin C. Engel ${ }^{1}$, Liesl J. Zühlke ${ }^{3}$, James B. Dale ${ }^{4}$ and Mark E. Engel ${ }^{\text {1* }}$

${ }^{1}$ Department of Medicine, Faculty of Health Sciences, University of Cape Town, Cape Town, South Africa, ${ }^{2}$ Division of Cardiology, Children's National Health System, Washington, DC, United States, ${ }^{3}$ Children's Heart Disease Research Unit, Department of Paediatrics, University of Cape Town, Cape Town, South Africa, ${ }^{4}$ Division of Infectious Diseases, University of Tennessee Health Science Center (UTHSC), Memphis, TN, United States
\end{abstract}

Background: Previous studies have established that streptococcal antibody titer is correlated with a diagnosis of acute rheumatic fever (ARF). However, results vary in the usefulness of GAS antibodies, particularly anti-streptolysin-O (ASO) and anti-DNase B, in confirming a recent GAS infection. Therefore, we sought to provide, from published studies, an evidence-based synthesis of the correlation of streptococcal serology to establish the usefulness of immunological data in aiding the diagnosis of ARF. These findings are anticipated to have implications where echocardiography is not freely available, especially where ARF is rampant.

Methods: We conducted a comprehensive search across a number of databases. Applying a priori criteria, we selected articles reporting on studies, regardless of study design, that evaluate the levels of antibodies against GAS-specific antigens in ARF subjects against control values or a published standard. Data were extracted onto data extraction forms, captured electronically, and analyzed using Stata software. Risk of bias was assessed in included studies using the Newcastle-Ottawa Scale (NOS).

Results and Conclusion: The search strategy yielded 534 studies, from which 24 met the inclusion criteria, reporting on evaluation of titers for SLO $(n=10)$, DNase B $(n=9)$, anti-streptokinase (ASK) $(n=3)$ amongst others. Elevation in titers was determined by comparison with controls and upper limit of normal (ULN) antibody values as determined in healthy individuals. Meta-analysis of case-controlled studies revealed moderate odds ratio $(\mathrm{OR})$ correlations between ARF diagnosis and elevated titers for SLO (OR $=10.57$; 95\% Cl, 3.36-33.29; 10 studies) and DNAse B (OR = 6.97; 95\% Cl, 2.99-16.27; 7 studies). While providing support for incorporating SLO and DNase B in the diagnosis of ARF, we present the following reflections: an elevation in SLO and DNase B levels are not consistently associated with an ARF diagnosis; increasing the number of GAS proteins in the test is warranted to improve sensitivity; paired (acute and convalescent) samples could provide a more accurate indication of a rising titer. Use of community-based controls as a standard is not a reliable marker by which to gauge recent GAS infection.

Keywords: GAS antigens, anti-streptolysin-O, anti-DNase B, ARF diagnosis, systematic review 


\section{INTRODUCTION}

Acute rheumatic fever (ARF), which develops within 2-6 weeks after a preceding non-invasive group A streptococcal (GAS) infection such as streptococcal pharyngitis or scarlet fever, affects $\sim 300,000-500,000$ people across the globe each year, the majority of whom live in developing countries. ARF symptoms include fever, arthritis, carditis, rash (erythema marginatum), subcutaneous nodules, and/or Sydenham's chorea (1-3). Since these symptoms are related to other diseases, the Jones criteria has been used since 1944 as a clinical standard in the diagnosis of ARF and rheumatic heart disease (RHD); amongst its criteria, is laboratory evidence of recent streptococcal infection, either through culture or an elevation in serum streptococcal antibodies (3). An accurate diagnosis of ARF ensures proper treatment and reduces the risk of recurrent disease and the development of rheumatic heart disease (4). $\mathrm{ARF}$ is often underdiagnosed, by as much as $50 \%$, as reported in a Fijian hospital-based study which compared clinical data against primary care records from health care clinics (5). Okello similarly reports a likelihood of under-representation of the actual number of cases presenting to primary care in Uganda (6), thus highlighting the need to develop simple and practical approaches to diagnosing ARF in primary care in low-resource settings.

The Jones criteria (7) has recently been updated by the American Heart Association (AHA) to suit all types of populations with appropriate recommendations $(3,8)$. With recent advancements in medical technologies such as echocardiography and Doppler flow assessments, analyzing images of the heart valves has been made easier, with clinicians following the guidelines as described in the Jones criteria (3). However, these tools may not be readily available in areas where ARF is rampant. The Jones criteria has guidelines as to assess the remaining major clinical manifestations which, however, may be difficult to evaluate as these symptoms could be mistaken for or attributed to other illnesses. Symptoms of arthritis may be found in septic arthritis, juvenile idiopathic arthritis, lyme disease, or sickle cell anemia (9). Carditis may be found in mitral valve prolapse, fibroelastoma, cardiomyopathy, or Kawasaki disease. Symptoms associated with chorea may be found in Wilson disease, tic disorder, encephalitis, or other autoimmune diseases such as systemic lupus erythematosus and systemic vasculitis. Therefore, included in the Jones criteria are other mechanisms, such as evidence of a preceding GAS infection to eliminate any doubt in the diagnosis of ARF (9).

The Jones criteria describe evidence of a preceding GAS infection with any one of three scenarios; a positive throat culture for GAS, a positive GAS carbohydrate (GAC) antigen test, or a rise in GAS antibody titers [anti-streptolysin O (ASO) or antiDNase $B$ ] that requires paired samples (at diagnosis and 3 weeks post-suspected diagnosis) (9). These GAS-specific antigens form part of the arsenal of GAS for survival and infiltration of the bacteria into human tissues; thus, these antibodies are present in the sera of GAS-infected individuals (10-12). Streptolysin O (SLO) is a cytolytic toxin released by GAS for cell lysis $(13,14)$.
DNase B is an extracellular virulent protein with DNA-degrading activity $(15,16)$. These two virulent factors, along with GAC, are mentioned within the Jones criteria; however, there are many other GAS-specific antigens in recent times that have shown potential as putative biomarkers relating to the presence of GAS (17-24).

Few countries have specific guidelines in terms of an ARF diagnosis, specifically including a preceding GAS infection (Supplementary Table 1). We sought, through a comprehensive systematic review of published studies, to conduct an evidencebased synthesis of the utility of streptococcal serology in aiding the diagnosis of ARF. Primarily, our review aimed to assess available published literature regarding the association of antibodies against GAS antigens with ARF. We anticipate that our findings could have implications for the design of future diagnostic tests to confirm recent GAS infection in suspected ARF patients.

\section{METHODS}

\section{Search Strategy and Selection Criteria}

According to the Preferred Reporting Items for Systematic Reviews and Meta-Analyses guidelines (25), we performed a systematic literature review from two peer-reviewed databases (PubMed and Scopus) with predefined search terms (Supplementary Table 2). This review asks the following question: What is the utility of GAS serology, specifically SLO and/or DNase B, in providing evidence of a recent GAS infection in diagnosing ARF? In addition, we further sought to explore the potential of other GAS-specific antigens which may provide additional support of a recent GAS infection. The search strategy incorporated both free term text and Medical Subject Headings (MeSH) adapted to suit the particular database. Keywords incorporated a combination of terms relating to group A streptococcus, GAS antigens, SLO, DNase B, serology, immune response, and acute rheumatic fever. Results were complemented by hand searching and citation searches in Google Scholar. The search was not restricted to publication dates or language. Additionally, gray literature including theses and conference proceedings, were also considered for inclusion.

Studies were included if immunological assays were used to evaluate the expression of antibodies evoked by GAS-specific antigens in ARF cases and controls within the same population or the use of a control standard based on the titers of healthy individuals (upper limit of normal, ULN) from the same region. Cases needed to be clinically diagnosed as ARF (peerreviewed guidelines were not a prerequisite), while controls were documented as those having no history of ARF or RHD. In addition, longitudinal studies evaluating immune responses at more than one time point following new GAS acquisitions were also included. Case reports, narrative reviews, opinion pieces and publications lacking expression data, or referenced methodology and/or accepted guidelines, were excluded from the review. Duplicated studies of datasets and participants were removed, with the final, most recent, publication of the data assessed for inclusion. 


\section{Data Extraction and Article Management}

Two reviewers (TS, KR) independently applied the search strategy to the relevant databases. Articles were managed using the Rayyan QCRI web/mobile application (26). Titles and abstracts were evaluated to exclude studies that did not describe the expression of GAS-specific antibodies. Thereafter, full texts of the included titles and abstracts were retrieved and further evaluated against the inclusion criterion (Supplementary Table 3). Rayyan QCRI has a built-in "blind" filter function which prevented the reviewers from observing the other's judgements. Discrepancies were resolved through discussion, involving an arbitrator (third reviewer, $\mathrm{ME} / \mathrm{BM}$ ) where necessary.

Two reviewers (TS, BM) extracted data using a standardized data extraction form and any contradictions were solved through discussion with another of the reviewers (ME). Search results from the databases listed above, published and unpublished studies were managed with Endnote X9 referencing software. Briefly, data extraction consisted of recording the study demographics (number of study participants, geographical region), diagnostic measures, GAS-specific antigens and relevant antibody titer measurements describing elevation. The risk of bias assessment tool (Supplementary Table 4) established by Wells et al. (27) was adapted in questions specific for use in this review, for assessing bias amongst included articles. Using the Newcastle-Ottawa Quality Assessment Scale (NOS) for casecontrol studies, which were characterized as being of a low or high risk of bias. A study with a low risk of bias is considered to be of high-quality and a low-quality study, with a higher risk of bias. Risk of bias was incorporated into the evaluation of heterogeneity in the pooled analyses.

\section{Data Analysis}

Odds ratio estimates together with their $95 \%$ confidence intervals (CIs) were calculated to represent the association between GASspecific antigens and ARF. The Mantel-Haenszel method was used to pool together odds data from individual studies (28). Variability between studies was evaluated both by assessing forest plots visually, and formally by the heterogeneity tests using $\chi^{2}$ based $Q$ and $I^{2}$ statistic (29). As expected, the studies varied in the constitution of participants and in the types of assays conducted; thus, a random-effects model was used for analysis (30).

We conducted statistical data analyses using Stata version 14.1 (StataCorp, College Station, TX, USA) to estimate the combined effect size (odds ratio and 95\% CIs) between GAS antigens and ARF and to generate comparative effect forest plots. Studies were analyzed in subgroups based on the inclusion of an accepted guideline at the time of diagnosis of ARF cases. Where a meta-analysis was not feasible, either because data were too heterogeneous or insufficient to allow for meaningful pooling, we compiled a narrative report of the results. Antigens, for which only a single study was available, thus precluding conducting a meta-analysis, were presented as an odds ratio with its $95 \%$ confidence interval (CI). We utilized the respective authors' definition of ULN in defining a rising titer.

\section{RESULTS}

\section{Overview of Search Strategy and Included Articles}

Our search strategy yielded 534 articles which reduced to 479 after excluding duplicates (Figure 1). An additional five studies were included through citation searching, thus leaving 484 for consideration for this review. Following screening of titles and abstracts, 53 articles were deemed potentially relevant and available for full-text evaluation. Twenty-four studies met the inclusion criteria, of which 14 were amenable to metaanalysis. Table 1 shows the characteristics of the included studies. The included articles were published between 1955 and 2020 with sample sizes (cases and controls) ranging from 43 to 2,118 enrolled participants. Studies were conducted in local and university hospitals, clinics, outpatient departments, and schools situated in the study areas. Studies were conducted in the USA $(n=7)$, Japan $(n=5)$, India $(n=4)$, Egypt $(n=3)$, with one article from each of Pakistan, Trinidad, Madagascar, Ethiopia, UK, Australia, and New Zealand. Participants ranged in age from 1 to 89 years. All the articles narrowed their target population to a specific age group, mainly that of children. Only one article (41) made an effort to obtain participants from any age group so as to reflect the national population. A list of the excluded studies with accompanying reasons are detailed in Supplementary Table 5.

The overall quality of studies was moderate, with 12 studies deemed as having a low risk of bias (i.e., a high NOS score; Supplementary Table 4). The included studies clearly described the phenotypes of patients, providing an acceptable case definition and guideline or diagnostic algorithm. Studies diagnosed ARF according to the Jones criteria, with controls examined as having no prior history of ARF or RHD from the same population and age-matched to the cases. Seven of the studies classed as of high risk of bias (NOS <5) were completed before 1990 with authors failing to clearly define the controls or cases with appropriate diagnostic guidelines $(33-35,37,39,43,52)$. One study Zainab et al. (53) recruited no controls but instead used an ULN cut-off published previously from within the same region.

\section{Association of SLO Antibody With ARF}

Ten studies (11 populations; controls, $n=1,972$; cases, $n=$ 1,947) providing data on Anti-SLO titers were amenable to metaanalysis (Figure 2).

Overall, ARF cases showed a greater association of an SLO antibody rise in comparison to controls [odds ratio (OR), 10.57 (95\% CI [3.36, 33.29]; $\left.\left.\left(I^{2}, 77.7 \%\right)\right)\right]$. In a subgroup analysis according to whether a guideline for the diagnosis of ARF was used or not, the association was not found to be statistically significant among studies not utilizing a guideline. Amongst studies not included in the meta-analysis due to the absence of a control group, each report a rise in anti-SLO titer: Zainab (53) in 24 of 50 cases (48\%) of ARF diagnosed according to the Jones criteria (published standard $=200 \mathrm{IU} / \mathrm{ml}$ ), Saini (48) in 15 of 26 (58\%) cases of ARF as per the Jones criteria guideline (published 


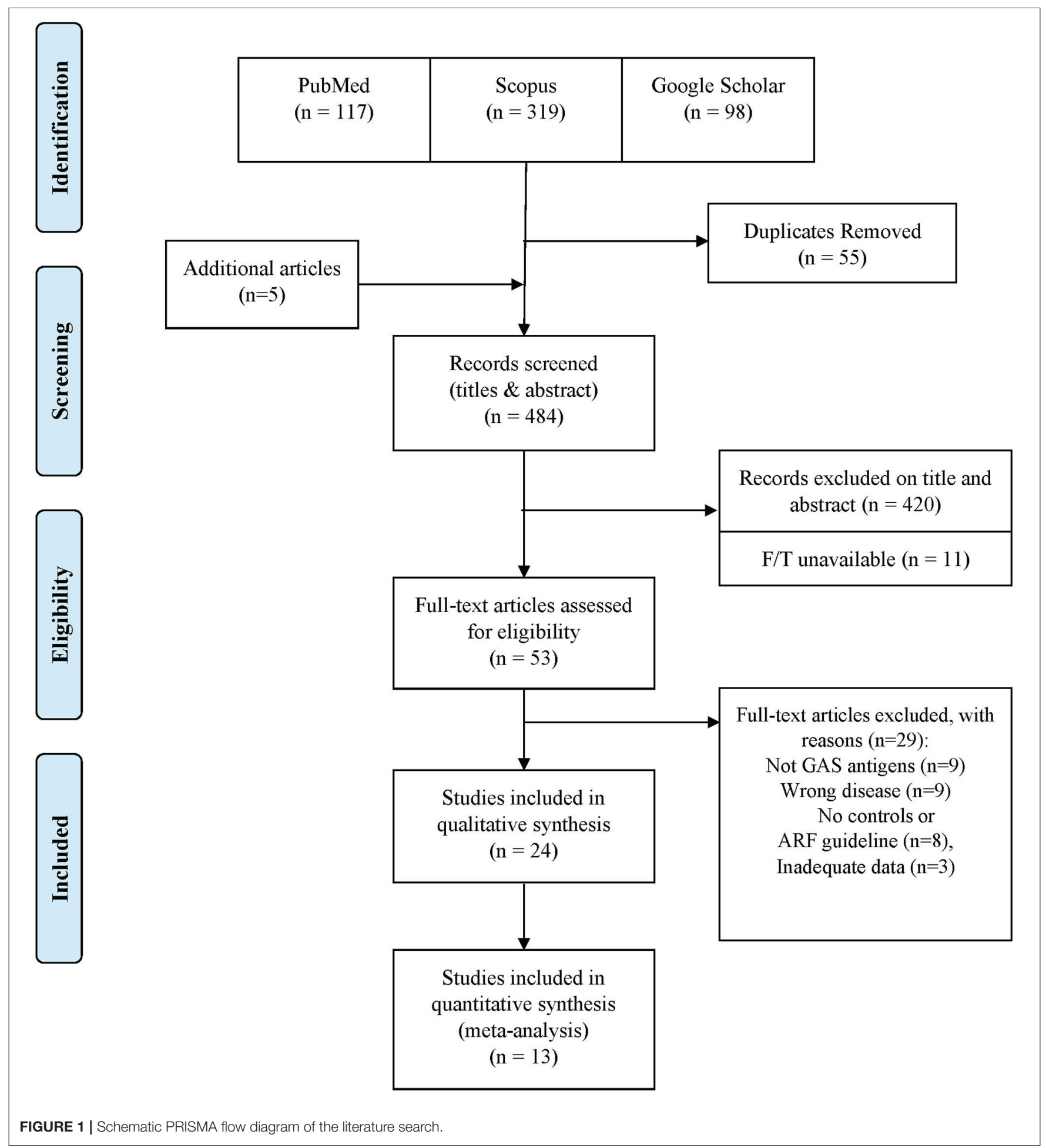

standard $=262 \mathrm{IU} / \mathrm{ml}$ ), Hokonohara (39) in 24 of 67 cases of ARF (36\%) against published standard $=240 \mathrm{IU} / \mathrm{ml}$.

\section{Association of DNase B Antibody With ARF}

Nine studies provided data on Anti-DNase B titers, of which seven (cases, $n=164$, controls, $n=1,031$ ) were amenable to meta-analysis (Figure 3). DNase B antibody levels were significantly increased in ARF cases [OR, 6.97 (95\% CI [2.99, 16.27]; $\left.\left.\left(I^{2}, 67.4 \%\right)\right)\right]$ in comparison to controls. This result was consistent across all studies, irrespective of the use of a guideline in diagnosing ARF cases. The two studies not included in the meta-analysis did not have control groups as a comparator. Saini 
TABLE 1 | Characteristics of included studies.

\begin{tabular}{|c|c|c|c|c|c|c|}
\hline Study ID & Country & Setting & $\begin{array}{l}\text { Diagnostic } \\
\text { guideline }\end{array}$ & Antigen/Detection method & Participants & Age \\
\hline aAyoub et al. (31) & Grenada/USA & ND & Jones criteria & $\begin{array}{l}\text { SLO, DNase B, and GAC-assays } \\
\text { described in previous publication (not } \\
\text { available) }\end{array}$ & $\begin{array}{l}\text { Grenada: } \operatorname{RF}(n=32), \\
\text { controls }(n=30) \\
\text { Florida: } \operatorname{RF}(n=32), \\
\text { controls }(n=32)\end{array}$ & $5-32$ years \\
\hline bDas et al. (32) & USA/India & ND & NCS & $\begin{array}{l}\text { DNase B-ELISA vs. DNA methyl } \\
\text { green micromethod }\end{array}$ & $\begin{array}{l}\text { ARF (20), controls }(n= \\
\text { 20) }\end{array}$ & ND \\
\hline $\begin{array}{l}{ }^{a} F u j i k a w a \text { and } \\
\text { Ohkuni (33) }\end{array}$ & Japan & ND & $\begin{array}{l}\text { RF and RHD } \\
\text { Guideline of } \\
\text { Japanese } \\
\text { Circulation Society }\end{array}$ & $\begin{array}{l}\text { SLO-streptozyme test, } \\
\text { DNase B-hemoprobe B test, } \\
\text { GAC-ASP kit, } \\
\text { SE-enzyme } \\
\text { antibody-antigen reaction }\end{array}$ & $\begin{array}{l}\text { RF }(n=8), \text { controls }(n \\
=354)\end{array}$ & $6-15$ years \\
\hline $\begin{array}{l}\text { aFujikawa and } \\
\text { Okuni (34) }\end{array}$ & Japan & ND & $\begin{array}{l}\text { RF and RHD } \\
\text { Guideline of } \\
\text { Japanese } \\
\text { Circulation Society }\end{array}$ & $\begin{array}{l}\text { SLO, DNase B, and SK-multiple } \\
\text { enzyme test (streptozyme test) }\end{array}$ & $\begin{array}{l}\operatorname{RF}(n=21) \text {, controls }(n \\
=178)\end{array}$ & $6-15$ years \\
\hline $\begin{array}{l}\text { a Fujikawa et al. } \\
\text { (35) }\end{array}$ & Japan & ND & $\begin{array}{l}\text { RF and RHD } \\
\text { Guideline of } \\
\text { Japanese } \\
\text { Circulation Society }\end{array}$ & $\begin{array}{l}\text { SLO-described previously, } \\
\text { DNase B-hemoprobe B test }\end{array}$ & $\begin{array}{l}\operatorname{RF}(n=46), \text { controls }(n \\
=278)\end{array}$ & $\begin{array}{l}3 \text { age groups: } \\
<6,6-16 \text {, and } \\
>16 \text { years }\end{array}$ \\
\hline $\begin{array}{l}{ }^{\mathrm{b}} \text { Gomaa et al. } \\
\text { (36) }\end{array}$ & Egypt & $\begin{array}{l}\text { Outpatient } \\
\text { RF Clinic }\end{array}$ & Jones criteria & $\begin{array}{l}\text { SLO-turbidimetric immunoassay } \\
\text { and ELISA }\end{array}$ & $\begin{array}{l}\text { ARF }(n=80), \text { controls } \\
(n=80)\end{array}$ & $\begin{array}{l}\text { ARF--14.5 } \\
\text { years (mean), } \\
\text { control- } \\
-15.2 \text { yrs } \\
\text { (mean) }\end{array}$ \\
\hline aHalbert et al. (37) & USA & ND & NCS & SLO-agar precipitin technique & $\begin{array}{l}\operatorname{RF}(n=33), \text { non-RF }(n \\
=35)\end{array}$ & ND \\
\hline $\begin{array}{l}\text { aHanson-Manful } \\
\text { et al. (38) }\end{array}$ & New Zealand & Hospitals & Jones criteria & $\begin{array}{l}\text { SLO - turbidimetric technique using } \\
\text { SLO kit, } \\
\text { DNase B-enzyme inhibition assay, } \\
\text { SpnA-bead-based immunoassay }\end{array}$ & $\begin{array}{l}\text { ARF }(n=16), \text { controls } \\
(n=36)\end{array}$ & $\begin{array}{l}\text { ARF--10.6 } \\
\text { years (mean), } \\
\text { Controls- } \\
\text {-6yrs (mean) }\end{array}$ \\
\hline $\begin{array}{l}\text { aHokonohara et } \\
\text { al. (39) }\end{array}$ & Japan & ND & NCS & $\begin{array}{l}\text { SLO-described by other author } \\
\text { DNase B-hemoprobe B test, } \\
\text { GAC - hemagglutination method }\end{array}$ & $\begin{array}{l}\text { RF }(n=28), \text { controls }(n \\
=\text { NCS })\end{array}$ & $5-16$ years \\
\hline $\begin{array}{l}\text { d Hysmith et al. } \\
(40)\end{array}$ & USA & $\begin{array}{l}\text { University } \\
\text { associated } \\
\text { clinics }\end{array}$ & - & $\begin{array}{l}\text { SLO, DNase B, SCPA, Mrp, J14, } \\
\text { SpyCEP, SSE, SOF, SpyAD, and } \\
\text { FBP54-ELISA }\end{array}$ & PIDs $(n=41)$ & $6-15$ years \\
\hline $\begin{array}{l}\text { dJohnson et al. } \\
(12)\end{array}$ & USA & $\begin{array}{l}\text { University } \\
\text { associated } \\
\text { clinics }\end{array}$ & - & SLO and DNase B-ELISA & PIDs $(n=160)$ & $6-15$ years \\
\hline a Julie et al. (41) & Madagascar & Hospital & NCS & SLO-latex agglutination technique & $\begin{array}{l}\operatorname{ARF}(n=1,690) \\
\text { control }(n=428)\end{array}$ & $1-89$ years \\
\hline ¿Kaplan et al. (42) & USA & NCS & - & $\begin{array}{l}\text { SLO, DNase B, and NADase-assays } \\
\text { described in previous publication (not } \\
\text { available) }\end{array}$ & PIDs $(n=49)$ & $3-6$ years \\
\hline $\begin{array}{l}\text { a Kawakita et al. } \\
\text { (43) }\end{array}$ & Japan & $\begin{array}{l}\text { Elementary } \\
\text { school }\end{array}$ & NCS & $\begin{array}{l}\text { SLO_spectrophotometric method, } \\
\text { DNase B-micro method, } \\
\text { NADase-reduction by } \\
\text { alcohol dehydrogenase }\end{array}$ & $\begin{array}{l}\text { ARF }(n=3), \text { controls }(n \\
=361)\end{array}$ & $6-11$ years \\
\hline aKotby et al. (44) & Egypt & Hospital & Jones criteria & SLO-rapid latex agglutination & $\begin{array}{l}\text { ARF }(n=60), \text { controls } \\
(n=200)\end{array}$ & $\begin{array}{l}3 \text { age groups: } \\
<6,6-10, \text { and } \\
>10 \text { years }\end{array}$ \\
\hline${ }^{b}$ Read et al. (45) & Trinidad & Hospital & Jones criteria & SLO-antibody titre kit & $\begin{array}{l}\mathrm{RF}(n=44) \text {, controls }(n \\
=34)\end{array}$ & ND \\
\hline${ }^{b}$ Read et al. (46) & USA & Hospital & $\begin{array}{l}\text { Rheumatic Fever } \\
\text { Service of The } \\
\text { Rockefeller } \\
\text { University Hospital }\end{array}$ & $\begin{array}{l}\text { SLO-in vitro cellular migration of } \\
\text { white blood cells }\end{array}$ & $\begin{array}{l}\mathrm{RF}(n=\mathrm{NCS}), \text { controls } \\
(n=\mathrm{NCS})\end{array}$ & ND \\
\hline
\end{tabular}


TABLE 1 | Continued

\begin{tabular}{|c|c|c|c|c|c|c|}
\hline Study ID & Country & Setting & $\begin{array}{l}\text { Diagnostic } \\
\text { guideline }\end{array}$ & Antigen/Detection method & Participants & Age \\
\hline 'Sagar et al. (47) & India & ND & Jones criteria & SCI, SCPA, and PSA-ELISA & $\begin{array}{l}\text { RF }(n=24), \text { controls }(n \\
=25)\end{array}$ & ND \\
\hline asaini et al. (48) & India & Hospital & Jones criteria & SLO-NCS & $\begin{array}{l}\text { ARF }(n=26), \text { controls } \\
(n=84)\end{array}$ & $5-15$ years \\
\hline dShet et al. (49) & USA & NCS & - & SLO, DNase B, and SCPA-ELISA & PIDs $(n=202)$ & $2-12$ years \\
\hline $\begin{array}{l}\text { bTewodros et al. } \\
\text { (50) }\end{array}$ & Ethiopia & ND & NCS & SK-ELISA & $\begin{array}{l}\text { ARF }(n=11), \text { controls } \\
(n=10)\end{array}$ & $3-12$ years \\
\hline $\begin{array}{l}\text { bThakur and } \\
\text { Prakash (51) }\end{array}$ & India & ND & NCS & GAC-ELISA & $\begin{array}{l}\text { ARF }(n=50), \text { controls } \\
(n=50)\end{array}$ & ND \\
\hline $\begin{array}{l}\text { aWiddowson et } \\
\text { al. (52) }\end{array}$ & UK & $\begin{array}{l}\text { Outpatient } \\
\text { clinic }\end{array}$ & NCS & $\begin{array}{l}\text { SLO-spectrophotometric method, } \\
\text { DNase B-micro method }\end{array}$ & $\begin{array}{l}\text { RF group }(n=6) \\
\text { controls }(n=44)\end{array}$ & $16-18$ years \\
\hline aZainab et al. (53) & Pakistan & Hospital & Jones criteria & SLO-kit human tex ASOT & $\begin{array}{l}\operatorname{ARF}(n=50) \\
\text { (Historic control values) }\end{array}$ & $5-15$ years \\
\hline
\end{tabular}

ND, no data; NCS, not clearly stated; RF, rheumatic fever; PIDs, participants.

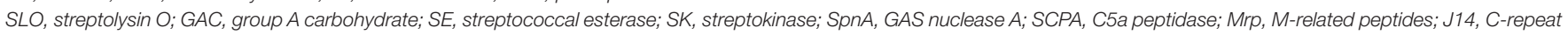

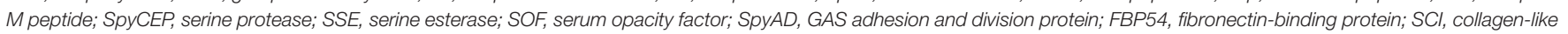
surface protein; PSA, putative surface antigen.

a Meta-analysis.

${ }^{b}$ Mean titer data.

c Single article-antigen.

${ }^{d}$ Longitudinal data.

(48), used a published standard of $134 \mathrm{IU} / \mathrm{ml}$ and reported an elevation of anti-DNase B titers in $85 \%$ (22 of 26) of cases while Hokonohara (39), had 41 cases of ARF and showed a 60\% $(n=$ 25) titer elevation.

A sensitivity analysis revealed a reduction in the association of anti-SLO levels with ARF in studies with low-risk scores for bias [OR, 4.87 (95\% CI, 1.07-22.17); $I^{2}$, 93.1\%]. Anti-DNase B meta-analysis comprising studies of a low risk of bias, revealed a non-statistically significant association between antibody titers and ARF.

\section{Association of Other GAS-Specific Antigens With ARF: Streptokinase and GAS Carbohydrate}

Three studies provided data on anti-streptokinase (ASK) titers, of which only two (controls, $n=532$; cases, $n=29$ ) were amenable to meta-analysis (Figure 4) while two studies (controls, $n=$ 416; cases, $n=72$ ) provided data on Anti-GAC (AGAC) titers (Figure 4).

ASK antibody levels were significantly increased in ARF patients [OR, 5.09 (95\% CI [2.07, 12.50], $\left.\left.\left(I^{2}, 13 \%\right)\right)\right]$ while GAC responses showed no significance in elevation between cases and controls [OR, 2.79 (95\% CI [0.87, 8.99]; $\left.\left.\left(I^{2}, 67.2 \%\right)\right)\right]$. Hokonohara (39), not included in the meta-analysis, showed an elevation of 54\% (36 of 67) for ASK and 45\% (19 of 41) for AGAC titers in cases of ARF.

\section{Narrative Review of Studies Not Included in the Meta-Analysis}

Four studies $(12,40,42,49)$ reported on the longitudinal assessment of human immune responses to GAS-specific antigens following a new GAS acquisition. Kaplan (42), in evaluating the immune response of 49 participants (aged 3-6 years) against SLO, DNase B, and NADase antigens, showed that GAS pharyngeal-infected participants had an elevated response to GAS antigens compared with participants without infection: SLO, $57 \%$ increase vs. $22 \%$, DNase B, 50 vs. $11 \%$ and NADase, 43 vs. $22 \%$. Johnson (12) reported on the immune response of 160 participants (aged 6-15 years), from whom 3,491 cultures and 1,679 serum samples were obtained. Over the study period they identified 58 new GAS acquisitions in 45 participants, of which $34.5 \%(n=20)$ of the participants showed a significant increase in SLO and DNase B titers. Thirty-six (62.1\%) GAS acquisitions were associated with an increase in antibody titer to SLO or DNase B, while 28 showed an increase to SLO and 28 for DNase B. Thus, had only SLO or only DNase B antibody titers been analyzed, eight GAS acquisitions would have been missed. Johnson (12), provided evidence that of 54 serum samples for ASO and 51 samples for anti-DNase B showing an increase in titer following a new GAS acquisition, $60 \%$ were below the ULN described, resulting in the mischaracterization of preceding GAS infections. Furthermore, in amongst GAS carriers, 239 samples had an increased ASO titer above the ULN and 307 samples for anti-DNase B, while only 9.6\% (ASO) and 6.5\% (anti-DNase B) of these were associated with a true titer increase following a GAS acquisition. It was also shown that in the absence of a culture-positive for GAS, ASO, and anti-DNase B titers were still higher than the ULN for extended periods of time. The study by Hysmith (40) presents the most recent and comprehensive investigation of antibody responses following GAS acquisition. From 41 participants (aged 6-15 years) over a period of 2 years, 51 new GAS acquisitions were documented, with 34 showing an increase in antibody titers against SLO and/or DNase B, illustrating an overall sensitivity of $67 \%$ in predicting a new 


\section{GAS Antigens in Acute Rheumatic Fever anti-SLO levels}

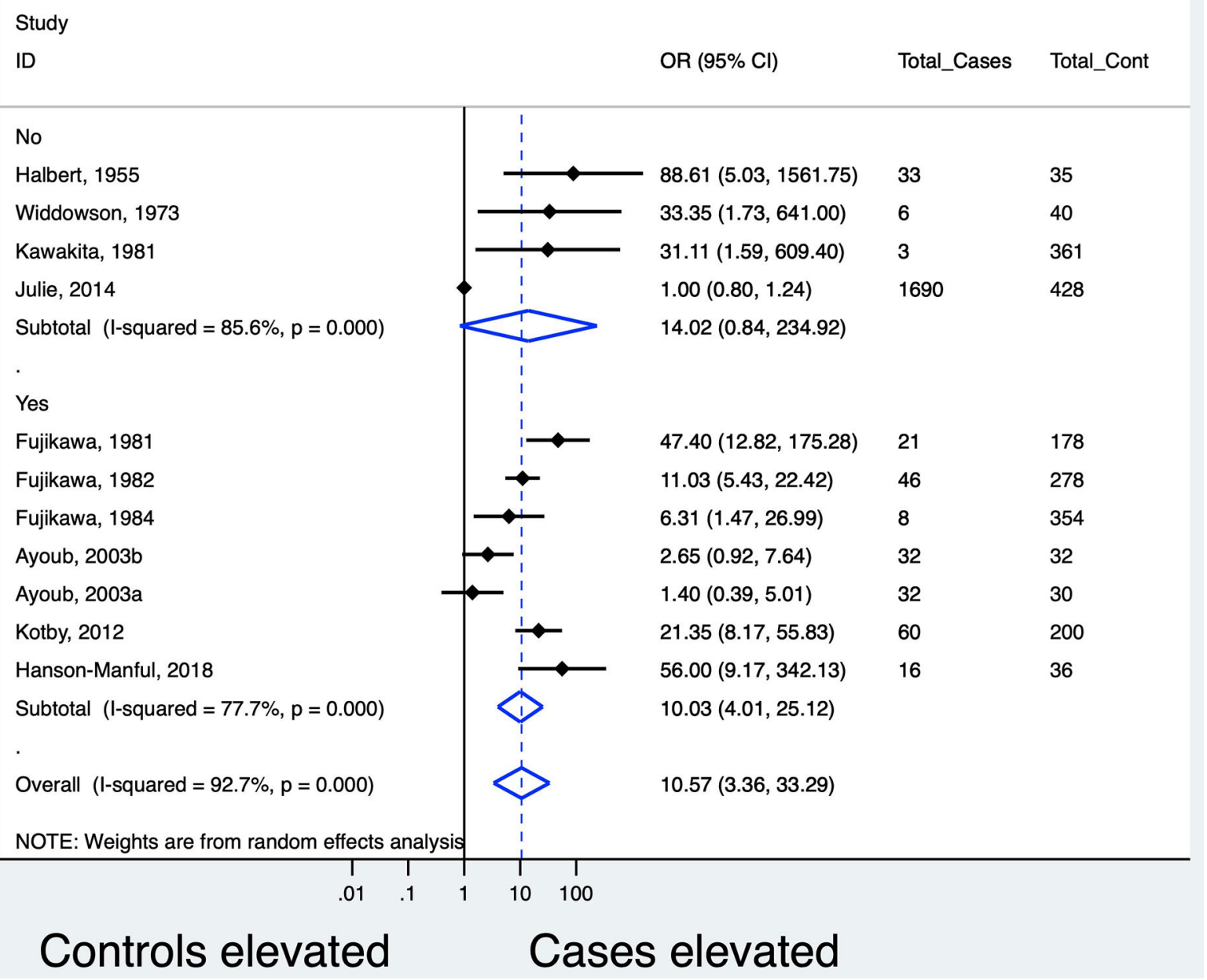

FIGURE 2 | Forest plot evaluating the odds of association between anti-SLO titers and ARF; subgrouping based on whether a guideline was used to diagnose ARF cases.

GAS acquisition. Adding increases in antibody levels to GAS SCPA (C5a peptidase) and one additional GAS-shared antigen to SLO and DNase B antibody level increases, improved the overall sensitivity to 76 and $98 \%$, respectively.

Studies that only reported average mean titers were summarized in Supplementary Table 6, provided data were available for SK (50), SLO $(36,45,46), \operatorname{GAC}(51)$, and DNase $B$ (32). In all the studies, the average mean titers from cases of ARF were considerably higher in comparison to that of the controls.

Studies reporting on less common GAS antigens are summarized in Supplementary Table 7, with the use of GASspecific antigens: GAS nuclease A (Spn A) (38), collagen-like surface protein (SCI), putative surface antigen (PSA), SCPA (54), streptococcal esterase (SE) (33), Nicotinamide adenine dinucleotidase (NADase) (43), and superoxide dismutase (SOD)
(55), in which only Spn A showed a significant OR (95\% CI, 56.00 [9.17; 342.13]).

\section{DISCUSSION}

We have presented a comprehensive review of the literature on group A streptococcal antibody responses and their utility in making the clinical diagnosis of ARF. Our meta-analysis provides evidence for a significant association between ARF and anti-SLO, anti-DNase B, and ASK, thus indicating the usefulness of these immunological markers in supporting an ARF diagnosis. This finding is supported by individual studies showing a consistently higher average mean titer in ARF cases over controls. However, there is currently no evidence of an association between GAC antibodies and ARF. 


\section{GAS Antigens in Acute Rheumatic Fever DNAse B levels}

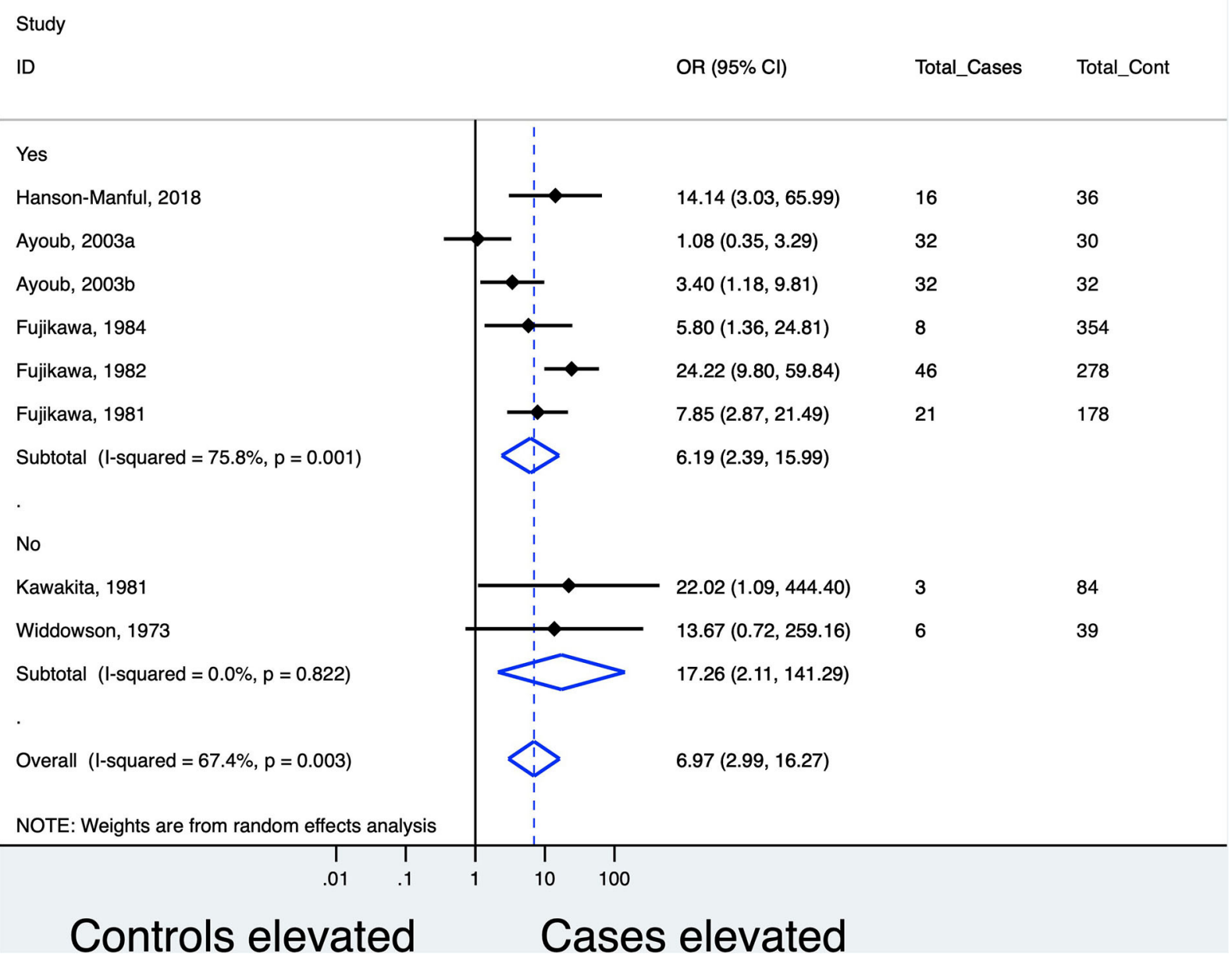

FIGURE 3 | Forest plot evaluating the odds of association between anti-DNase B titers and ARF; subgrouping based on whether a guideline was used to diagnose ARF cases.

We grouped our findings according to whether peer-reviewed guidelines were used in the clinical diagnosis of ARF. Excluding studies which did not employ a guideline, i.e., those classified as having a higher risk of bias in terms of case definition, reduced the combined estimate of association for anti-SLO and antiDNase B with ARF from OR 10.57 (95\% CI $[3.36,33.29]$ ) to OR 10.03 (95\% CI $[4.01,25.12])$ and OR 6.97 (95\% CI [2.99, $16.27])$ to OR 6.19 (95\% CI $[2.39,15.99])$, respectively. This may indicate caution in terms of investigating only a single antigen in establishing an ARF diagnosis.

Given differences in techniques used to measure antibody titers across the studies, sample size variation, regional differences resulting in the variation of ULN titer levels and published standards used (Table 1), a high degree of heterogeneity was to be expected; hence we employed the random-effect model for the meta-analysis. Sensitivity analyses of studies with a low risk of bias score revealed a reduction in, although still significant, the association of anti-SLO levels with ARF while anti-DNase B analyses showed no statistically significant association between antibody titers and ARF. Unfortunately, the dearth of studies precluded conducting further meaningful subgroup analyses.

We provide a summary of literature meeting our inclusion criteria, but not amenable to meta-analysis through a narrative review. Additional single antigen studies provide further support for the significant association of SK, SLO, GAC, DNase B, Spn A, and SE with ARF but not for SCI, PSA, SCPA, and SOD. For completeness, though not encompassing ARF cases, we included four studies reporting on the longitudinal assessment of human immune response to GAS-specific antigens following a new GAS acquisition in acute and convalescent samples. The studies provided meaningful data in terms of the effectiveness of SLO, 


\section{GAS Antigens in Acute Rheumatic Fever}

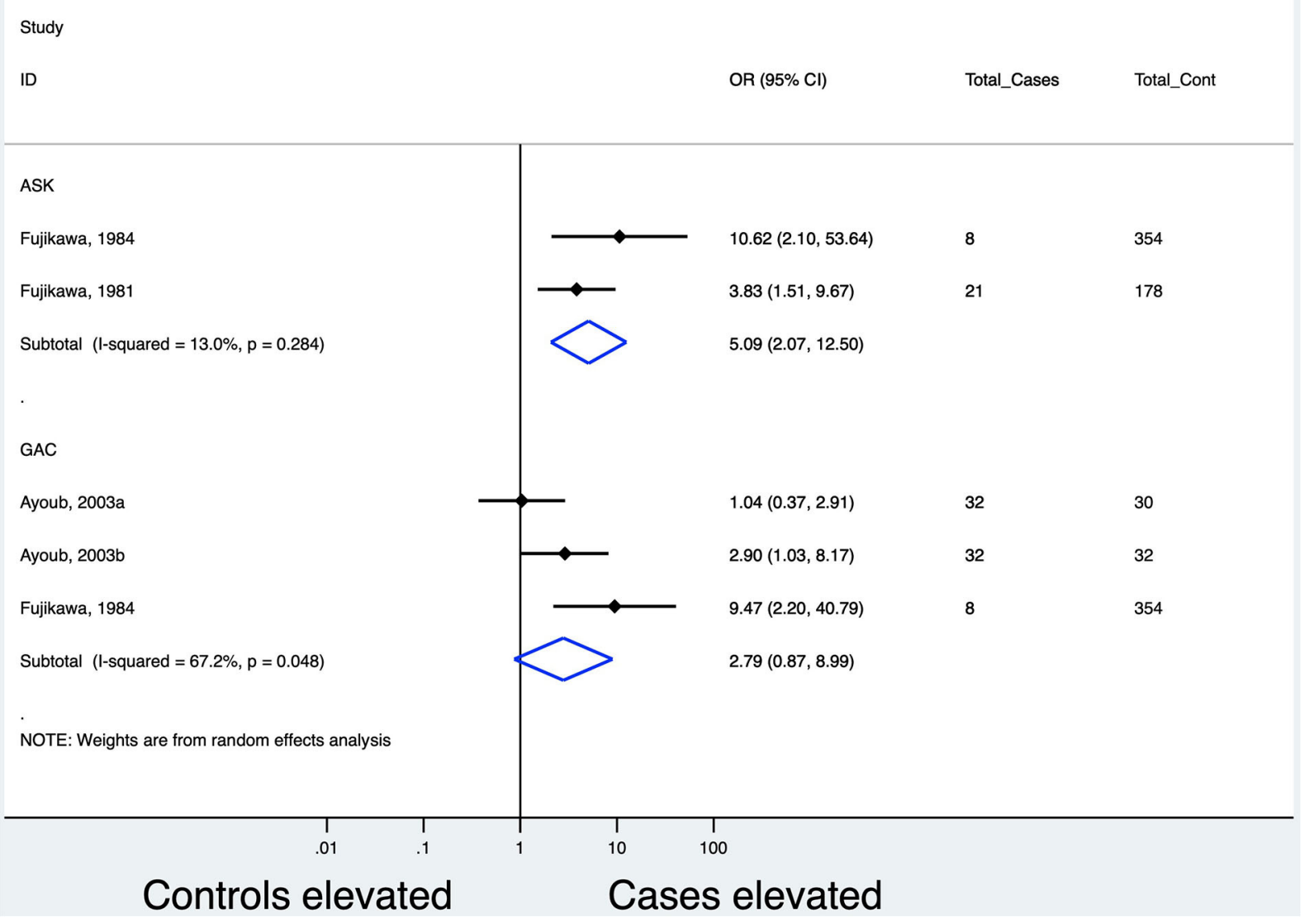

FIGURE 4 | Forest plot evaluating the odds of association between anti-ASK and anti-GAC titers and ARF; subgrouping based on antigen.

DNase B, NADase, and other antigens in detecting a preceding GAS infection. These findings suggest the need to employ an array of antigens to increase the sensitivity of assays confirming a preceding GAS infection, that could be amended within a ARF diagnostic guideline.

Within the studies reporting study limitations, the use of the ULN to describe elevation in titers as evidence of a recent infection risk confounding given its dependence on the controls used within the study. Numerous reports suggest that the ULN of antibody titers against GAS antigens varies with age and geographical location. It has also been reported that titers are lower in adults in comparison with children $(56,57)$. Johnson (12) and Hysmith (40) identified a number of cases where the participant showed an increase in titer following a new GAS acquisition where the peak titers did not exceed the ULN described for the specific population. Given that cases of GAS carriers demonstrated prolonged elevated responses that exceeded the ULN, caution is warranted since using ULN solely to describe elevation may result in false-negative or false-positive GAS-associations. Thus, these studies strongly suggest that evaluating the rise in titer in paired sequential samples as the most effective way in describing a preceding GAS infection.

This systematic review employed rigorous methods as proposed by the Cochrane Collaboration (58) in synthesizing published resources on the utility of GAS serology in confirming a preceding GAS infection. However, the availability of individual patient data would have further enhanced our findings. As is often the case, data were not reported so as to allow inclusion of some studies into the meta-analysis. Also, there remains a lack of studies in this area.

\section{CONCLUSION AND FUTURE RESEARCH}

Providing evidence for a preceding GAS infection remains a challenge. Future studies to evaluate serological tests for evidence of a preceding GAS infection should be designed to overcome the major limitations of the existing evidence base. This can be readily accomplished by ensuring a well-defined case definition as in clear symptoms of ARF with paired sequential sampling of the target population. Furthermore, utilizing an array of GAS 
antigens is more likely to provide greater sensitivity in providing evidence of a recent infection.

\section{DATA AVAILABILITY STATEMENT}

The original contributions presented in the study are included in the article/Supplementary Material, further inquiries can be directed to the corresponding author/s.

\section{AUTHOR CONTRIBUTIONS}

MS, BM, and ME were jointly responsible for the conceptualization of the study. MS, KR, BM, and KE contributed to the search strategy and performed data extraction. MS and ME designed and executed the analyses, wrote the first draft, and revised drafts of the manuscript. JD and LZ contributed to the interpretation of the findings. All authors have read and approved the final manuscript.

\section{REFERENCES}

1. World Health Organization. Rheumatic Fever and Rheumatic Heart Disease: Report of a WHO Expert Consultation. Geneva: World Health Organization (2004).

2. Bhardwaj R, Sood A. Clinical profile of acute rheumatic fever patients in a tertiary care institute in present era. J Assoc Phys India. (2015) 63:22-4. Available online at: www.crossref.org

3. Gewitz MH, Baltimore RS, Tani LY, Sable CA, Shulman ST, Carapetis J, et al. Revision of the Jones Criteria for the diagnosis of acute rheumatic fever in the era of Doppler echocardiography: a scientific statement from the American Heart Association. Circulation. (2015) 131:1806-18. doi: 10.1161/CIR.0000000000000205

4. Ralph AP, Noonan S, Wade V, Currie BJ. The 2020 Australian guideline for prevention, diagnosis and management of acute rheumatic fever and rheumatic heart disease. Med J Aust. (2021) 214:220-7. doi: $10.5694 / \mathrm{mja} 2.50851$

5. Parks T, Kado J, Colquhoun S, Carapetis J, Steer A. Underdiagnosis of acute rheumatic fever in primary care settings in a developing country. Trop Med Int Health. (2009) 14:1407-13. doi: 10.1111/j.1365-3156.2009. 02385.x

6. Okello E, Wanzhu Z, Musoke C, Kakande B, Mondo CK, Freers J, et al. Cardiovascular complications in newly diagnosed rheumatic heart disease patients at Mulago Hospital, Uganda. Cardiovasc J Afr. (2013) 24:82. doi: 10.5830/CVJA-2013-004

7. Dajani AS, Ayoub E, Bierman FZ, Bisno AL, Denny FW, Durack D, et al. Guidelines for the diagnosis of rheumatic fever: Jones criteria, updated 1992: special writing group of the committee on rheumatic fever, endocarditis, and Kawasaki disease of the council on cardiovascular disease in the young, American Heart Association. Circulation. (1993) 87.

8. Ferrieri P. Proceedings of the Jones Criteria workshop. Circulation. (2002) 106:2521-3. doi: 10.1161/01.CIR.0000037745.65929.FA

9. Gerber MA, Baltimore RS, Eaton CB, Gewitz M, Rowley AH, Shulman ST, et al. Prevention of rheumatic fever and diagnosis and treatment of acute Streptococcal pharyngitis: a scientific statement from the American Heart Association Rheumatic Fever, Endocarditis, and Kawasaki Disease Committee of the Council on Cardiovascular Disease in the Young, the Interdisciplinary Council on Functional Genomics and Translational Biology, and the Interdisciplinary Council on Quality of Care and Outcomes Research: endorsed by the American Academy of Pediatrics. Circulation. (2009) 119:1541-51. doi: 10.1161/CIRCULATIONAHA.109.191959

\section{FUNDING}

This work was based on the research supported in part by the National Research Foundation of South Africa (grant number 116287). Any opinion, finding, conclusion, or recommendation expressed in this material was that of the authors, and the NRF does not accept any liability in this regard. MS, KR, BM, KE, JD, and ME were supported by grant (NW17SFRN33630027) from the American Heart Association. JD received funds from the U.S. Public Health Service (NIH grants R01 AI-132117 and R01 AI-010085).

\section{SUPPLEMENTARY MATERIAL}

The Supplementary Material for this article can be found online at: https://www.frontiersin.org/articles/10.3389/fcvm. 2021.691646/full\#supplementary-material

10. Gerber MA, Gray ED, Ferrieri P, Kaplan EL. Enzyme-linked immunosorbent assay of antibodies in human sera to streptococcal DNase B. J Lab Clin Med. (1980) 95:258-65.

11. Podbielski A, Zarges I, Flosdorff A, Weber-Heynemann J. Molecular characterization of a major serotype M49 group A streptococcal DNase gene (sdaD). Infect Immun. (1996) 64:5349-56. doi: 10.1128/iai.64.12.5349-5356.1996

12. Johnson DR, Kurlan R, Leckman J, Kaplan EL. The human immune response to streptococcal extracellular antigens: clinical, diagnostic, and potential pathogenetic implications. Clin Infect Dis. (2010) 50:481-90. doi: 10.1086/650167

13. Fontaine MC, Lee JJ, Kehoe MA. Combined contributions of streptolysin $\mathrm{O}$ and streptolysin $\mathrm{S}$ to virulence of serotype M5 streptococcus pyogenes strain Manfredo. Infect Immun. (2003) 71:3857-65. doi: 10.1128/IAI.71.7.3857-3865.2003

14. O'Seaghdha M, Wessels MR. Streptolysin O and its co-toxin NADglycohydrolase protect group A streptococcus from Xenophagic killing. PLoS Pathog. (2013) 9:e1003394. doi: 10.1371/journal.ppat.1003394

15. Broudy TB, Pancholi V, Fischetti VA. The in vitro interaction of streptococcus pyogenes with human pharyngeal cells induces a phage-encoded extracellular DNase. Infect Immun. (2002) 70:2805-11. doi: 10.1128/IAI.70.6.2805-2811.2002

16. Buchanan JT, Simpson AJ, Aziz RK, Liu GY, Kristian SA, Kotb M, et al. DNase expression allows the pathogen group A streptococcus to escape killing in neutrophil extracellular traps. Curr Biol. (2006) 16:396-400. doi: 10.1016/j.cub.2005.12.039

17. Cleary PP, Prahbu U, Dale J, Wexler D, Handley J. Streptococcal C5a peptidase is a highly specific endopeptidase. Infect Immun. (1992) 60:5219-23. doi: 10.1128/iai.60.12.5219-5223.1992

18. Courtney HS, Dale JB, Hasty D. Differential effects of the streptococcal fibronectin-binding protein, FBP54, on adhesion of group A streptococci to human buccal cells and HEp-2 tissue culture cells. Infect Immun. (1996) 64:2415-9. doi: 10.1128/iai.64.7.24152419.1996

19. Courtney HS, Dale JB, Hasty DL. Mapping the fibrinogen-binding domain of serum opacity factor of group a streptococci. Curr Microbiol. (2002) 44:236-40. doi: 10.1007/s00284-001-0037-1

20. Batzloff M, Hayman W, Davies M, Zeng M, Pruksakorn S, Brandt E, et al. Protection against group A streptococcus by immunization with J8-diphtheria toxoid: contribution of J8-and diphtheria toxoid-specific antibodies to protection. J Infect Dis. (2003) 187:1598-608. doi: 10.1086/ 374800 
21. Sabharwal H, Michon F, Nelson D, Dong W, Fuchs K, Manjarrez RC, et al. Group A Streptococcus (GAS) carbohydrate as an immunogen for protection against GAS infection. J Infect Dis. (2006) 193:129-35. doi: 10.1086/ 498618

22. Liu M, Zhu H, Zhang J, Lei B. Active and passive immunizations with the streptococcal esterase Sse protect mice against subcutaneous infection with group A streptococci. Infect Immun. (2007) 75:3651-7. doi: 10.1128/IAI.00038-07

23. Penfound TA, Chiang EY, Ahmed EA, Dale JB. Protective efficacy of group A streptococcal vaccines containing type-specific and conserved $\mathrm{M}$ protein epitopes. Vaccine. (2010) 28:5017-22. doi: 10.1016/j.vaccine.2010. 05.018

24. Dale JB, Niedermeyer SE, Agbaosi T, Hysmith ND, Penfound TA, Hohn $\mathrm{CM}$, et al. Protective immunogenicity of group A streptococcal M-related proteins. Clin Vaccine Immunol. (2015) 22:344-50. doi: 10.1128/CVI. 00795-14

25. Page MJ, McKenzie JE, Bossuyt PM, Boutron I, Hoffmann TC, Mulrow CD, et al. The PRISMA 2020 statement: an updated guideline for reporting systematic reviews. Syst Rev. (2021) 10:89. doi: 10.1186/s13643-02101626-4

26. Ouzzani M, Hammady H, Fedorowicz Z, Elmagarmid A. Rayyan-a web and mobile app for systematic reviews. Syst Rev. (2016) 5:210. doi: 10.1186/s13643-016-0384-4

27. Wells GA, Shea B, O'Connell D, Peterson J, Welch V, Losos M, et al. The Newcastle-Ottawa Scale (NOS) for Assessing the Quality of Nonrandomised studies in Meta-Analyses [webpage on the Internet]. Ottawa, ON: Ottawa Hospital Research Institute (2011). Available online at: http://www.ohri.ca/ programs/clinical_epidemiology/oxford.asp

28. Robins J, Greenland S, Breslow NE. A general estimator for the variance of the Mantel-Haenszel odds ratio. Am J Epidemiol. (1986) 124:719-23. doi: 10.1093/oxfordjournals.aje.a114447

29. Higgins JPT, Thomas J, Chandler J, Cumpston M, Li T, Page MJ, et al., editors. Cochrane Handbook for Systematic Reviews of Interventions version 6.2 (updated February 2021). Cochrane (2021). Available online at: www.training. cochrane.org/handbook

30. Borenstein M, Hedges LV, Higgins JP, Rothstein HR. A basic introduction to fixed-effect and random-effects models for meta-analysis. Res Synth Methods. (2010) 1:97-111. doi: 10.1002/jrsm.12

31. Ayoub EM, Nelson B, Shulman ST, Barrett DJ, Campbell JD, Armstrong G, et al. Group A streptococcal antibodies in subjects with or without rheumatic fever in areas with high or low incidences of rheumatic fever. Clin Diagn Lab Immunol. (2003) 10:886-90. doi: 10.1128/CDLI.10.5.886-890.2003

32. Das S, Dileepan T, Johnson D, Kaplan E, Cleary PP. Enzyme-linked immunosorbent assay for group A streptococcal anti-DNase B in human sera, using recombinant proteins-comparison to the DNA methyl green micromethod. J Immunol Methods. (2017) 451:111-7. doi: 10.1016/j.jim.2017.09.006

33. Fujikawa S, Ohkuni M. Clinical significance of Anti-streptococcal Esterase (ASE) determination in rheumatic fever and other streptococcal diseases: the 8 th conference on prevention for rheumatic fever and rheumatic heart disease. Jpn Circ J. (1984) 48:1330-3. doi: 10.1253/jcj.48.1330

34. Fujikawa S, Okuni M. Diagnosis of streptococcal infection: previous or recent: proceedings of the 5 th conference on prevention for rheumatic fever and rheumatic heart disease. Jpn Circ J. (1981) 45:1382-3. doi: 10.1253/jcj. 45.1382

35. Fujikawa S, Kawakita S, Kosakai N, Oda T, Ohkuni M, Shiokawa Y, et al. Significance of anti-deoxyribonuclease-B (ADN-B) determination in clinical practice: the 6th conference on prevention for rheumatic fever and rheumatic heart disease. Jpn Circ J. (1982) 46:1180-3. doi: 10.1253/jcj. 46.1180

36. Gomaa MH, Ali SS, Fattouh AM, Hamza HS, Badr MM. MBL2 gene polymorphism rs1800450 and rheumatic fever with and without rheumatic heart disease: an Egyptian pilot study. Pediatr Rheumatol. (2018) 16:24. doi: 10.1186/s12969-018-0245-x

37. Halbert SP, Swick L, Sonn C. The use of precipitin analysis in agar for the study of human streptococcal infections: II. Ouchterlony and Oakley technics. J Exper Med. (1955) 101:557-76. doi: 10.1084/jem.101.5.557
38. Hanson-Manful P, Whitcombe AL, Young PG, Carr PEA, Bell A, Didsbury $A$, et al. The novel group A streptococcus antigen SpnA combined with bead-based immunoassay technology improves streptococcal serology for the diagnosis of acute rheumatic fever. J Infect. (2018) 76:361-8. doi: 10.1016/j.jinf.2017.12.008

39. Hokonohara M, Yoshinaga M, Baba Y. Study of antibody response to 4 streptococcal antigens in rheumatic fever and kawasaki disease with or without cardiovascular lesions: the 11th conference on prevention for rheumatic fever and rheumatic heart disease. Jpn Circ J. (1987) 51:1353-6. doi: $10.1253 /$ jcj.51.1353

40. Hysmith ND, Kaplan EL, Cleary PP, Johnson DR, Penfound TA, Dale JB. Prospective longitudinal analysis of immune responses in pediatric subjects after pharyngeal acquisition of group A streptococci. J Pediatric Infect Dis Soc. (2017) 6:187-96. doi: 10.1093/jpids/piw070

41. Julie ZN, Arivelo RZ, Hendriso RD, Ramamonjisoa A, Andry R. Current practice about the evaluation of antibody to streptolysin O (ASO) levels by physicians working in Antananarivo, Madagascar. Afr Health Sci. (2014) 14:384-9. doi: 10.4314/ahs.v14i2.14

42. Kaplan EL, Top FH Jr, Dudding BA, Wannamaker LW. Diagnosis of streptococcal pharyngitis: differentiation of active infection from the carrier state in the symptomatic child. J Infect Dis. (1971) 123:490-501. doi: 10.1093/infdis/123.5.490

43. Kawakita S, Takeuchi T, Inoue J, Onishi T, Uemura Y. Infection of group A streptococcus and antibody response to extracellular antigens. Jpn Circ J. (1981) 45:1384-90. doi: 10.1253/jcj.45.1384

44. Kotby AA, Habeeb NM, Ezz El Arab S. Antistreptolysin O titer in health and disease: levels and significance. Pediatr Rep. (2012) 4:25-9. doi: $10.4081 /$ pr.2012.e8

45. Read S, Reid H, Fischetti V, Poon-King T, Ramkissoon R, McDowell M, et al. Serial studies on the cellular immune response to streptococcal antigens in acute and convalescent rheumatic fever patients in Trinidad. J Clin Immunol. (1986) 6:433-41. doi: 10.1007/BF00915249

46. Read SE, Fischetti VA, Utermohlen V, Falk RE, Zabriskie JB. Cellular reactivity studies to streptococcal antigens migration inhibition studies in patients with streptococcal infections and reheumatic fever. J Clin Invest. (1974) 54:439-50. doi: 10.1172/JCI107780

47. Sagar V, Bergmann R, Nerlich A, McMillan DJ, Schmitz DPN, Chhatwal GS. Variability in the distribution of genes encoding virulence factors and putative extracellular proteins of streptococcus pyogenes in India, a region with high streptococcal disease burden, and implication for development of a regional multisubunit vaccine. Clin Vaccine Immunol. (2012) 19:1818-25. doi: 10.1128/CVI.00112-12

48. Saini N, Kumar D, Swarnim S, Bhatt D, Kishore S. Comparison of antistreptolysin $\mathrm{O}$ and anti-deoxyribonucleic $\mathrm{B}$ titers in healthy children to those with acute pharyngitis, acute rheumatic fever, and rheumatic heart disease aged 5-15 years. Ann Pediatr Cardiol. (2019) 12:195. doi: 10.4103/apc.APC_60_18

49. Shet A, Kaplan EL, Johnson DR, Cleary PP. Immune response to group A streptococcal C5a peptidase in children: implications for vaccine development. J Infect Dis. (2003) 188:809-17. doi: 10.1086/377700

50. Tewodros W, Norgren M, Kronvall G. Streptokinase activity among group A streptococci in relation to streptokinase genotype, plasminogen binding, and disease manifestations. Microb Pathog. (1995) 18:53-65. doi: 10.1016/S0882-4010(05)80012-9

51. Thakur A, Prakash K. Detection of antibody to C-carbohydrate of group A streptococci with enzyme-treated whole bacterial cells as antigen for ELISA. $J$ Med Microbiol. (1996) 45:214-8. doi: 10.1099/00222615-45-3-214

52. Widdowson JP, Maxted W, Newrick C, Parkin D. An outbreak of streptococcal sore throat and rheumatic fever in a Royal Air Force Training camp; significance of serum antibody to $\mathrm{M}$-associated protein. Epidemiol Infect. (1974) 72:1-12. doi: 10.1017/S0022172400023135

53. Zainab S, Saleem N, Manzoor A, Khaliq S, Wasim A, Khaliq S, et al. Antistreptolysin $\mathrm{O}$ titer and C-reactive protein levels in pediatric patients of acute rheumatic fever. Profess Med J. (2020) 27:1335-9. doi: 10.29309/TPMJ/2020.27.08.3336

54. Kumar R, Chakraborti A, Aggarwal A, Vohra H, Sagar V, Dhanda V, et al. streptococcus pyogenes pharyngitis and impetigo in a rural area of 
Panchkula district in Haryana, India. Indian J Med Res. (2012) 135:133. doi: 10.4103/0971-5916.93437

55. McMillan DJ, Davies MR, Good MF, Sriprakash KS. Immune response to superoxide dismutase in group A streptococcal infection. FEMS Immunol Med Microbiol. (2004) 40:249-56. doi: 10.1016/S0928-8244(04) 00003-3

56. Blyth CC, Robertson PW. Anti-streptococcal antibodies in the diagnosis of acute and post-streptococcal disease: streptokinase versus streptolysin $\mathrm{O}$ and deoxyribonuclease B. Pathology. (2006) 38:152-6. doi: 10.1080/003130206005 57060

57. Steer AC, Vidmar S, Ritika R, Kado J, Batzloff M, Jenney $\mathrm{AW}$, et al. Normal ranges of streptococcal antibody titers are similar whether streptococci are endemic to the setting or not. Clin Vaccine Immunol. (2009) 16:172-5. doi: 10.1128/CVI.00 291-08
58. Deeks J, Higgins J, Altman D, Green S. Cochrane Handbook for Systematic Reviews of Interventions Version 5.1. 0 (Updated March 2011). The Cochrane Collaboration (2011).

Conflict of Interest: The authors declare that the research was conducted in the absence of any commercial or financial relationships that could be construed as a potential conflict of interest.

Copyright $\odot 2021$ Salie, Rampersadh, Muhamed, Engel, Zühlke, Dale and Engel. This is an open-access article distributed under the terms of the Creative Commons Attribution License (CC BY). The use, distribution or reproduction in other forums is permitted, provided the original author(s) and the copyright owner(s) are credited and that the original publication in this journal is cited, in accordance with accepted academic practice. No use, distribution or reproduction is permitted which does not comply with these terms. 